\title{
ENTRE O DIZER E O ESCRITO: CORPO E LINGUAGEM NO ENSINO DE JACQUES LACAN
}

\section{José Guillermo Milán-Ramos}

\begin{abstract}
RESUMO
No presente trabalho, pretendo mostrar o estatuto do dizer e do escrito no ensino do psicanalista Jacques Lacan. Lacan realizou, ao longo de 26 anos ininterruptos, atividades de ensino em regime de seminário; ele mesmo realizou a recopilação de seus textos fundamentais, lançados em 1966 sob o título: Escritos ${ }^{1}$. Sabe-se também que um componente fundamental da sua doutrina é sua teoria sobre o estatuto do escrito na transmissão em psicanálise. Ao longo de seu ensino, também se preocupou por definir o estatuto do dizer. O dizer e o escrito aparecem enlaçados no ensino de Lacan em uma relação de temporalidade subjetiva, na qual a função essencial do dizer é a subjetivação do escrito, e isso se produz num tempo de espera no qual o corpo se vê comprometido pela própria inscrição da teoria no corpo (castração).
\end{abstract}

PALAVRAS-CHAVE

Oralidade; Escrita; Corpo; Psicanálise

\section{BETWEEN SAYING AND THE WRITING: BODY AND LANGUAGE IN THE TEACHING OF JACQUES LACAN}

\begin{abstract}
In the present work, I intend to show the saying and the writing statute in the teaching of psychoanalyst Jacques Lacan. Lacan carried throughout 26 years uninterrupted activities of teaching into the seminary regimen; he himself made the compilation of his basic texts, launched in 1966 under the heading: Writings. We also know that a basic component of his teaching is its theory on the writing statute in the psychoanalysis transmission. Throughout his teaching, he was also worried about defining the saying statute. Saying and the writing appear enlaced in the teaching of Lacan in a relation of subjective temporality, in which the essential function of saying (theory) is the subjectivation of the theoretical writing, and it is produced in an open assembly time in which the body itself is engaged for the proper inscription of the theory in the body (castration).
\end{abstract}

\section{KEYWORDS}

Oral language; Written language; Body; Psychoanalysis

\footnotetext{
${ }^{1}$ Cf. Lacan (1998).
} 
(...) [que] na escala em que devo aqui apresentar meu ensino, ele não se distancie demais da fala, cujas medidas diferentes são essenciais para o efeito de formação que procuro.

(LACAN, 1998c, p. 496-7)

Quais são as implicâncias fundamentais da fala e do escrito na transmissão em psicanálise? Os Escritos lacanianos, lançados em 1966, e o Seminário oral que Lacan apresentou durante 25 anos - com transcrição ainda em curso - constituem um corpus teórico verdadeiramente formidável. O Seminário e os Escritos são a trama, o enlace de um dizer e um escrito: fala intrincada num escrito; palavra sustentada e contida numa letra; instância da letra teórica parasitada pelo significante... Uma orientação, um movimento incessante: o escrito teórico se subjetiva pelo dizer. O sujeito, vestígio da circunstância de um dizer na cifra de um escrito.

O intrincamento entre escrito e dizer constituem a essência do estilo lacaniano de transmissão em psicanálise.

O escrito constitui uma instância, um momento fundamental de literalização da teoria. Cristalização-precipitação de enunciação em enunciado: no rigor do escrito teórico - do simples gesto de transcrição até o matema - sempre se marca a tendência à literalização da teoria. O cristal do escrito teórico é o efeito de uma precipitação, o momento de concluir - uma letra cai... - que segue a um tempo para compreender (LACAN, 1998a).

No gesto de literalização, a teorização/ transmissão psicanalíticas fazem um movimento de aproximação tangencial com a escrita da ciência. Em sua essência, então, a escrita teórica introduz e carrega as ilusões de uma metalinguagem científica, a fé na emergência de um enunciado derradeiro que encerre e capture as vicissitudes e contingenciamentos do ato de enunciação. Mas os contingenciamentos da enunciação constituem a própria condição de possibilidade do sujeito do inconsciente... Perigo, então - espreita, latência própria à dimensão da letra/enunciado -, de uma foraclusão da dimensão da subjetividade.

O dizer teórico - que guarda um certo grau de correspondência, uma contigüidade, com a leitura teórica - constitui o tempo seguinte desse escrito, o momento da nova dialetização daquele precipitado escrito, o momento em que a dimensão do significante é restituída à dimensão da letra e, através dele, a letra se subjetiva (um significante 
representa um sujeito para um outro significante). O significante parasita a letra, e a letra depende do significante para se subjetivar, para conjurar incessantemente o perigo da foraclusão do sujeito.

A dialetização da letra pelo dizer supõe sua entrada na matriz da temporalidade subjetiva: requer um tempo, tempo para compreender, tempo de atenção flutuante. Nesse tempo o significante latente na letra entra em ação, movimenta-se, o significante “desestabiliza” a letra, e o sujeito recebe os efeitos (subjetivantes) que podem advir da sua singular inscrição no campo do Outro. Entre o escrito e o oral, entre o dizer e a letra, há um tempo de espera, a atenção flutuante de um tempo para compreender, até que uma nova letra, eventualmente, precipita. Entre o escrito e o oral se constitui a própria trama da natureza inconsciente do pensamento teórico.

Nesse drama temporal o corpo recebe os efeitos. Angústia? Mal-estar? Desconforto? O corpo recebe os efeitos da “espera” do pensamento teórico. A fala e o escrito comprometem o corpo de modos diferentes. Isso nos orienta em relação às “medidas diferentes” da fala a respeito do escrito (cf. epígrafe). No seminário XXI, Lacan afirma: “que eu lhes faça passar pelas tripas (...), é a função do dizer, se eu não lhes digo, não será suficiente que o escreva” (LACAN, 1973-1974, p. 8). O corpo é caixa de ressonância do dizer teórico: pelo dizer, a letra teórica se inscreve no corpo (castração). ${ }^{2}$

Em seu livro A obra clara, Jean-Claude Milner (1996) realiza também uma interpretação a respeito da relação entre os escritos e os seminários na obra de Lacan, mas ele não postula esse tipo de dialética-temporalidade que queremos sustentar aqui. Milner propõe uma visão unilateral, dicotômica: “Se [a obra de Lacan] existe, ela está por inteiro nos Scripta”; “do ponto de vista do pensamento, nada há e jamais nada haverá a mais nos seminários do que nos Scripta. Mas sempre pode haver algo a mais nos Scripta do que nos seminários. Nada nos seminários pode modificar a interpretação dos Scripta”, etc. (MILNER, 1996, p.20).

Milner sustenta sua posição em que os seminários são "tecidos de protréptica” "procedimento discursivo que tem por função arrancar o sujeito da doxa a fim de voltá-lo para a theoria” (MILNER, 1996, p.18), isto é, alusões, floreios literários ou eruditos, diatribes, desconstrução da doxa... - enquanto os escritos "tendem a disso se livrar" (MILNER, 1996, p.18-19). Segundo Milner, os seminários “buscam capturar o ouvinte

\footnotetext{
${ }^{2}$ Cf. MILÁN-RAMOS (2006; 2007).
} 
(projetado, pela transcrição, em situação material de leitor, mas pouco importa) no ponto de imaginário onde a conjuntura do momento o colocou; tendo-o capturado, buscam desalojá-lo desse lugar natural através de um movimento violento, que em Lacan, ao contrário de Platão, toma de preferência a forma da diatribe, até mesmo da invectiva: diálogos monológicos e impolidos” (MILNER, 1996, p.19). Paralelamente, levando em conta que a escrita não se prestaria com tanta eficácia à provocação e à diatribe, Milner diz que na escrita lacaniana a protréptica negativa desenvolveu-se como "escrita artística”: "o lexema raro, o semantema inusitado, a sintaxe afetada devem impedir o leitor de se entregar a seu pendor lingüístico, fazê-lo desconfiar das sucessões lineares e das disposições simétricas, compeli-lo ao saber que advirá” (MILNER, 1996, p. 21-2). Ao mesmo tempo, ainda, Milner coloca uma ênfase positiva bem definida na prática lacaniana do semidizer e do bem dizer.

Um singular exemplo de violenta "protréptica” pode ser encontrado no Seminário XVII, quando Lacan se lança sobre os mitos freudianos - Édipo, Moisés, o pai da horda primordial de Totem e Tabu - realizando a operação teórica de passagem “do mito à estrutura” (LACAN, 1992). Lacan lê os três mitos freudianos numa tensão teórica violenta. Isso se figura em certos adjetivos e modalizações. Lacan diz que Freud retira todo o caráter mítico e trágico de Édipo (LACAN, 1992, p. 106), que “o grosseiro esquema assassinato do pai - gozo da mãe elide totalmente [sua] força trágica” (LACAN, 1992, p. 109), que o complexo de Édipo é “estritamente inutilizável” (LACAN, 1992, p. 93) ${ }^{3}$ para os analistas; também diz que o assassinato do pai da horda é uma "palhaçada darwiniana” (LACAN, 1992, p. 105); e, enfim, a hipótese do assassinato de Moisés já é “o cúmulo dos cúmulos” (LACAN, 1992, p. 108). Lacan pergunta: Que resulta de todo o que Freud articula? E responde: “Não o saber, mas a confusão” (LACAN, 1992, p. 13). Como se Lacan estivesse incomodado perante essa singular "protréptica freudiana do mito”... Como se os mitos freudianos fossem, em face à estrutura, apenas "protréptica”, e Lacan estivesse prestes a deles "se livrar” via literalização (escrita da estrutura)... Mas qual é o sentido dessa “confusão” introduzida pela “protréptica freudiana do mito”?:

Freud, é preciso dizer, sustenta um discurso estranho, o mais contrário à coerência, à consistência de um discurso. O sujeito do discurso não se sabe

\footnotetext{
${ }^{3}$ Em outras passagens do texto, Lacan modaliza: "De modo algum estou dizendo que o Édipo não serve para nada, ou que não tem relação alguma com o que nós fazemos. Para os psicanalistas, ele não serve para nada, lá isso é verdade, mas como os psicanalistas não são psicanalistas, isto nada prova. (...)" (LACAN, 1992, p. 105).
} 
como sujeito que sustenta o discurso. Que ele não saiba o que diz, ainda passa, sempre se o supriu. Mas o que diz Freud é que ele não sabe quem o diz.

O saber (...) é coisa que se diz, que é dita. Pois bem, o saber fala por conta própria - eis o inconsciente (LACAN, 1992, p. 66).

Agora parece que a incidência da protréptica freudiana do mito tem alguma coisa a ver com a colocação em jogo do inconsciente no ato mesmo de teorizar... Como se esse movimento violento funcionasse como um traço da tensão do gesto teórico lacaniano, criativo, "superador”. Lacan "força” e "violenta” o mito para conseguir "arrancar” dele a letra teórica. Daí nosso questionamento a Milner: essa linguagem violenta, “típica” dos seminários, pode ser reduzida a pura protréptica? Não existe aí uma relação estreita e definida do simples dizer com o semidizer e o bem dizer? ${ }^{4}$

Nós aqui tentamos figurar uma paisagem diferente, na qual certa teimosia do/sobre o significante - num movimento de insistência-persistência-desistência-retorno da teoria sobre si mesma - é parte fundamental do gesto teórico criativo e positivo, da subjetivação da/na teoria. A instância dos seminários lacanianos revela-se como um lugar fundamental para sua existência, para sua existência em ato. Trata-se de colocar a ênfase maior nos efeitos da palavra de Lacan sobre o próprio sujeito Lacan, na elaboração e subjetivação da letra lacaniana pelo dizer lacaniano, na exposição da escrita teórica ao significante inconsciente, instância essencial de seu bem dizer, e talvez retirar a ênfase dessa espécie de imagem de Lacan "pedagogo", que dedicava o maior esforço dos seus seminários a uma espécie de “protréptica” estéril teoricamente, sem maiores alcances teóricos, dirigida apenas a produzir um estratégico deslocamento nos ouvintes... No dizer lacaniano a protréptica existe, sem dúvida, mas seu alcance parece ser bem maior daquele que destacou Milner.

Em algumas passagens da leitura que Milner fez de Lacan, em A obra clara, há alguma coisa de congelamento na clareza, de ilusão retroativa adquirida sobre obra acabada. Para Milner, “pouco importa” a diferença entre a condição de ouvinte do

\footnotetext{
${ }^{4} \mathrm{O}$ não-reconhecimento de Milner da dimensão subjetivante da protréptica lacaniana se enraíza em certo "cientificismo" da sua leitura de Lacan, que também o levou, na sua interpretação da leitura lacaniana das categorias lógicas da modalidade (necessário, contingente, possível, impossível) a não demarcar com suficiente firmeza a diferença entre o possível (o que cessa de se escrever) - que se atualiza com toda sua força no dispositivo popperiano de refutabilidade de que depende a letra científica - e o inusitado do contingente (o que cessa de não se escrever), da qual depende diretamente a categoria de sujeito (cf. MILÁN-RAMOS, 2007).

Em relação a uma possível noção de autoria, a ênfase no enraizamento do pensamento teórico na fala/ dizer pode também conduzir a reflexão numa direção diferente àquela que apresenta Milner (1996).
} 
seminário e a de leitor da transcrição (MILNER, 1996, p. 19). Porém, deveria marcar-se uma diferença importante, relacionada à posição de “insistência” do/sobre o significante do leitor - na qual deve colocar-se o leitor - perante o texto lacaniano transcrito, somente comparável com a posição de insistência sobre a própria fala em que se situava Lacan quando proferia seus seminários (e, eventualmente, comparável também à do escritor perante o texto em curso, o texto sendo produzido). È nessa posição de insistência que acontecem os efeitos... A posição de ouvinte dos seminários, em relação à posição do leitor, em qualquer caso, apresenta diferenças que importam.

O estilo performático “provocador” de Lacan avança nessa direção, é uma estratégia para a inclusão da dimensão subjetiva na cena da teorização e na transmissão do saber em psicanálise. O movimento quase frenético que ele imprimia em seu pensamento; a diversidade e erudição das pressuposições de seu discurso; a nãocompreensão e o non-sens que, intermitentes, apoderavam-se do ouvinte/leitor; seus apelos ao auditório; a desorientação e o mal-estar que tudo isso muitas vezes provoca(va)...; enfim, o conjunto de elementos constitutivos do seu estilo apelativo, apontam nesta direção: despejar o caminho do sujeito do desejo na cena da teorizaçãotransmissão. Eles pressagiam, antecipam, anunciam, preparam o terreno, colocam em jogo..., são a primeira sombra do sujeito do inconsciente.

O original "estilo apelativo" de Lacan é um ato de reconhecimento: ele desloca e realça em ato os processos inconscientes (o recalque e o retorno do recalcado); ele mostra e faz operar no ato de teorização-transmissão o fato de que as resistências à psicanálise são internas à dimensão subjetiva, são constitutivas do objeto da psicanálise. Para dizê-lo de algum modo, seu estilo apelativo prepara o terreno, eleva a “temperatura” subjetiva: é um modo de atualizar, de expor-se e expor-nos à dimensão subjetiva, de não apagá-la nem esquecê-la, e a partir dai, a partir da experiência e dos efeitos que essa exposição suscita, fica(mos) numa posição melhor para apreender, reconhecer, incorporar, “experimentar” a natureza e o funcionamento dos processos inconscientes enquanto elementos constitutivos, determinantes e definitivos do pensamento teórico.

A relação com o dizer que seu estilo apelativo suscita prepara o terreno para a inclusão do sujeito na escrita da teoria. Este é o cerne do materialismo lacaniano: a inclusão em ato do sujeito na cena de teorização-transmissão é condição essencial para a inscrição da dimensão subjetiva na escrita (na borda do Simbólico) da teoria.

(c) ETD - Educação Temática Digital, Campinas, v.8, n. esp., p.264-276, jun. 2007-ISSN: 1676-2592. 269 
Para dizê-lo de outro modo, o estilo lacaniano supõe um movimento de incessante subjetivação de S(A), a letra que escreve o significante da falta no Outro, a letra que diz que não há metalinguagem. Quer dizer: há letra, mas não há metalinguagem.

Sempre corremos o risco de confundir, de fazer-passar o escrito por uma metalinguagem - o escrito se presta de bom grado, complacente, a essa confusão. Milner (1987), em O amor da língua, fala desse aspecto complacente do escrito com as derivas imaginárias, e do imbróglio ético que envolve:

\begin{abstract}
Quanto à língua, ela apresenta também efeito de deriva [imaginária]: preservando a sua identidade, ela não confere à alingua [lalangue] o que lhe é necessário para que uma coleção qualquer de falantes subsista? A saber, o mínimo de permanência que todo contrato exige e do qual a escrita se faz de bom grado suporte. Com isto, equivale a dizer que é preciso atribuir a língua inteira ao imaginário? É o que muitos sustentam. Mas será preciso admitir que gramáticas e dicionários, e que a escrita como tal, não atestam mais que o pavoneamento ao qual efetivamente eles se prestam muitas vezes? Dito ainda de outra forma, a língua é apenas uma máscara arbitrariamente construída sem tocar nenhum real? Tal é na verdade a inquietude que incomoda o lingüista, por pouco que a efetividade da psicanálise não lhe seja desconhecida (...).(MILNER, 1987, p. 16)
\end{abstract}

Encruzilhada do lingüista-cientista em face à ética do desejo. Continua Milner:

Pois se fosse absolutamente verdade que a língua não tocava nenhum real, seria o desejo do lingüista que se encontraria condenado à caricatura; em contrapartida, se os rumores no tocante à língua são infundados eles concorrem a um único fim: fazer o lingüista cessar em seu desejo [faire céder le linguiste sur son désir].

Iluminar a relação da alingua [lalangue] à língua implica, por conseguinte, a ética. (MILNER, 1987, p. 16)

A vertente imaginária da língua é subsidiária da escrita: a escrita se presta complacente às encenações metalingüísticas das gramáticas e dicionários, que tentam preservar a identidade da língua.

Essa “confusão”, o esforço incessante de fazer-passar o escrito por uma metalinguagem, é a própria matriz do discurso científico - e aí pode se pensar nos dois sentidos da palavra risco: risco de confundir a letra científica e a letra psicanalítica, precisamente como apagamento-cancelação: riscado do sujeito.

Para lidar com esse risco, com esse riscado, a letra requer um trabalho incessante de subjetivação. Não se trata, então, de fazer-passar o escrito por uma metalinguagem..., senão de subjetivar incessantemente o escrito: fazer do escrito parte, matéria de cifração, submetê-lo às contingências da homofonia. 


\title{
DOSSIÊ \\ Cuerpo, Lenguaje y Enseñanza Área Temática: Diferenças e Subjetividades em Educação
}

Uma posição de metalinguagem bem sucedida suporia a coincidência de enunciado e enunciação, o cancelamento da possibilidade de distingui-los. Para Lacan, um modo de subjetivar a letra S(A), o significante da falta no Outro, era precisamente se posicionando de um modo paródico no lugar de um Outro metalingüístico, não-barrado. Lacan fez dessa posição de metalinguagem alvo de inúmeras paródias, e para isso apelava ao que Zizek (1992) denominou de “enunciados impossíveis”:

\begin{abstract}
No Seminário XI, [Lacan] começa assim uma de suas frases. "Mas isso é precisamente o que eu quero dizer e o que digo - porque o que quero dizer é o que digo...". (...) [São] precisamente esses enunciados "impossíveis" enunciados que se ajustam à lógica do paradoxo "eu minto" - eles mantêm aberta a brecha fundamental do processo significante e desse modo impedem que assumamos uma posição de metalinguagem.

(...) ¿Não deixa claro um procedimento desse tipo (...) de modo quase palpável, a total impossibilidade de ocupar essa posição? ¿Não é, por absurdo, infinitamente mais subversivo que o poeticismo que proíbe todo enunciado direto e simples e se sente obrigado sempre a agregar novos comentários, ressalvas, digressiones, colchetes, pontos de interrogação... - tantas seguridades de que o que dizemos não se há de tomar direta ou literalmente como idêntico a si mesmo?

A metalinguagem não é só uma entidade Imaginária. É Real no estrito sentido lacaniano - isto é, é impossível ocupar a posição de [metalinguagem]. Mas, Lacan agrega, é ainda mais difícil simplesmente esquivar-se dela. No pode ser alcançada, mas também não pode ser evadida. Por isso a única maneira de esquivar o Real é produzir um enunciado de pura metalinguagem que, por seu patente absurdo, materialize sua própria impossibilidade: a saber, um elemento paradoxal que, em sua própria identidade, encarne a alteridade absoluta, a fenda irreparável que faz impossível ocupar uma posição de metalinguagem (ZIZEK, 1992, p. 204-205).
\end{abstract}

O alvo da paródia lacaniana era qualquer posição de metalinguagem. Por que escolher a paródia, um procedimento tão particular? A forma grega aéido significa "eu canto”. Dela derivou-se paraéido, “eu canto em conformidade a (outra coisa)” e paródía, “imitação burlesca de uma obra literária”. Mas a “imitação burlesca” lacaniana de posição de metalinguagem envolve um componente ético: por assim dizê-lo, esse traço de estilo é para ser levado a sério.

Enunciados impossíveis: “o que eu quero dizer é o que eu digo...”; também “Eu, a verdade, falo”, a escandalosa prosopopéia que Lacan (1998b) introduz no texto "A coisa freudiana...”: no nível do conteúdo, esses enunciados só afirmam a certeza da metalinguagem, o locutor agenciando o lugar da verdade, anulando a distância entre enunciado e enunciação ao fazer dessa distância o alvo de (potencialmente infinitos) comentários, ressalvas, esclarecimentos... quer dizer, de um esforço de incluí-la 


\section{DOSSIÊ \\ Cuerpo, Lenguaje y Enseñanza Área Temática: Diferenças e Subjetividades em Educação}

antecipadamente no enunciado, de fazê-la conteúdo ou referente do enunciado ${ }^{5}$...; mas ao mesmo tempo Lacan satura o enunciado com elementos de dêixis indiciais que tensionam ao máximo a dimensão da enunciação - elementos pertencentes ao código da língua, mas que seu sentido depende de fatores variáveis de uma situação de enunciação para outra: eles enfatizam, sublinham, a dimensão de ato, de frase atualizada, frase assumida por um locutor particular, em circunstâncias subjetivas, espaço-temporais precisas. Por assim dizê-lo, Lacan verte o “conteúdo” metalingüístico auto-referencial num recipiente cheio de "buracos” enunciativo-indiciais, produzindo um efeito patentemente absurdo ("na sua própria identidade encarna a alteridade absoluta”), efeito paradoxal, paródia metalingüística de encenação da hiância irreparável entre enunciado e enunciação. ${ }^{6}$ Nos exemplos em questão, esse jogo se produz em relação ao “eu”, a "quem fala” e suas intenções.

Zizek (1992) mostra a relação dessa brecha fundamental no Simbólico com a dimensão de perda-impotência-impossibilidade que encarna o significante fálico:

(...) para Lacan só a presença de um "pelo menos um” paradoxal sustenta a dimensão radical da fenda. O nome lacaniano desse elemento paradoxal é, claro, o falo como significante, uma espécie de versão negativa da "verdade como indicadora de si mesma”. O significante fálico é, por assim dizê-lo, um indicador de sua própria impossibilidade. Em sua própria positividade é o significante da "castração" - isto é, de sua própria falta. Os chamados objetos pré-fálicos (seios, excremento) são objetos perdidos, enquanto que o falo não está simplesmente perdido, senão que é um objeto que dá corpo a uma determinada e fundamental perda com sua presença. Com o falo, a perda enquanto tal adquire existência positiva. (...) (ZIZEK, 1992, p. 205-206)

\footnotetext{
${ }^{5}$ Essa questão abre para a polêmica entre o lacanismo e a desconstrução, no campo da ética da linguagem. Zizek (1992, p. 201ss) destaca a insistência lacaniana em uma concepção da psicanálise enquanto "experiência de verdade", em disjunção com a "esteticização universalizada" pós-estruturalista, na qual a verdade acabaria reduzida a um efeito de estilo da articulação discursiva - a verdade como "efeito de verdade" do texto. O tom da crítica é pungente: "Como deixar de reconhecer - pergunta Zizek - no zelo apaixonado com que o pós-estruturalista insiste em que todo texto, o seu incluído, está preso numa ambigüidade fundamental e inundado pela 'disseminação' do processo textual, os signos de uma denegação (no sentido freudiano de Verneinung), um reconhecimento apenas encoberto do fato de que falamos a partir de uma posição segura, uma posição que não está ameaçada pelo processo textual descentrado? Essa é a razão de que o poeticismo pós-estruturalista seja em último término afetado” (ZIZEK, 1992, p. 203).

${ }^{6} \mathrm{O}$ seguinte comentário de Zizek sobre Popper coloca um exemplo a contrário: “(...) poderia responder-se que o falso e pretensioso é precisamente a 'modesta' perspectiva relativista à maneira de Karl Popper, que pretende ter consciência de sus próprias limitações ('só é possível aproximar-se assimptoticamente à verdade, só temos aceso a fragmentos de conhecimentos que em qualquer momento é possível que se demonstre que são falsos'): a própria posição de enunciação dessas proposições desmente seu enunciado modesto, dado que assume um ponto de vista neutro, excetuado, a partir do qual pode subtrair-se a um julgamento sobre a limitação de seu conteúdo (...)” (ZIZEK, 1998, p. 283).
} 


\section{DOSSIÊ \\ Cuerpo, Lenguaje y Enseñanza Área Temática: Diferenças e Subjetividades em Educação}

O significante fálico, “indicador da sua própria impossibilidade”. Estabelece-se assim um ponto eletivo da lógica da falta-e-do-resto que circunscreve os limites da potência do significante: $\Phi$

Como afirma Zizek, a metalinguagem não pode ser alcançada, mas também não podemos esquivar-nos dela: a linguagem em si mesma inclui uma perspectiva de metalinguagem, que se equivale com o nível do enunciado. Por assim dizê-lo, essa propensão, essa “vocação” metalingüística é estruturalmente constitutiva da linguagem, mas no contexto da relação moderna entre sujeito e linguagem ela desata e manifesta toda sua potência. Na nossa fala, o nível do enunciado atualiza permanentemente um "horizonte de metalinguagem", que se faz presente como um esforço constante por procurar “dizer o que realmente queremos dizer”. Como seres de linguagem, então, estamos fatalmente fadados a essa "perspectiva metalingüística”, somos permanentemente ludibriados, “enganados” por ela... Mas há formas e formas de deixar-se enganar!

A encruzilhada ética do sujeito neurótico moderno (sujeito da ciência, correlato do sujeito da psicanálise) tem raiz linguajeira. Nessa encruzilhada se sugerem dois horizontes, duas vias intrincadas que definem seu campo e o alcance de suas apostas: (i) a via da reflexividade significada e trabalhada como divisão subjetiva, como escuta do desejo; e (ii) a via de uma reflexividade auto-negada significada e trabalhada a partir do "ideal” ou "vocação" de metalinguagem do discurso da ciência, que, em si mesmo, contém uma espécie de "mecanismo auto-negador" da dimensão subjetiva - o discurso da ciência se define precisamente pelo "esforço impossível” de cancelar-foracluir a dimensão subjetiva (LACAN, 1998d). Os dois - o sujeito reflexivo e o mecanismo metalingüístico autonegador da dimensão subjetiva - são puro efeito de linguagem. Os dois, como tendências subjetivas alternantes, claudicantes, ou como emblemas de endereçamentos éticos apostas subjetivas - alternativos, representam duas relações possíveis com a linguagem, duas “experiências” possíveis de linguagem.

Melman (2003) faz referência ao modo em que esse drama de linguagem se atualiza para o sujeito da civilização científica:

Eis, ainda, um traço da nova economia psíquica: não há mais divisão subjetiva, o sujeito não é mais dividido. É um sujeito bruto. Falar de sujeito dividido é já dizer que ele se interroga sobre sua própria existência, que ele introduz em sua vida, em sua maneira de pensar uma dialética, uma oposição, uma reflexão, uma maneira de dizer 'Não'. Hoje em dia, quase não vemos a expressão do que seria a divisão subjetiva (MELMAN, 2003, p. 27). 


\section{DOSSIÊ \\ Cuerpo, Lenguaje y Enseñanza \\ Área Temática: Diferenças e Subjetividades em Educação}

E ainda:

[Penso] que não vamos na direção de uma desaparição do inconsciente, no sentido freudiano do termo, mas na do sujeito do inconsciente. Lidaremos de certo modo com um inconsciente que não terá mais interlocutor. Não haverá mais nem vontade de se fazer reconhecer, nem enunciação a título de sujeito. Teremos um singular, um estranho retorno ao que era a situação pré-cartesiana, de antes da aparição do 'eu [je]' do cogito. Haverá vozes das profundezas, vozes diabólicas que o sujeito não reconhecerá como suas. (MELMAN, 2003, p. 124). ${ }^{7}$

A própria linguagem possibilita a distância de si mesmo que constitui a essência reflexiva do sujeito moderno. Essa distância é, por natureza, precária, claudicante, elusiva. ${ }^{8}$ Mas a paródia permite "fincar” essa distância por um momento, colocando-a no centro da cena: a paródia atualiza e significa essa distância, renovando-a em ato. Permite ao sujeito "praticar” a distância de si mesmo, apontando a "distância interna” entre fala e metalinguagem. O sujeito moderno, cartesiano, por definição, duvida de suas certezas, suspeita das armadilhas e ambigüidades da linguagem...: a paródia é uma posta em cena da dúvida metódica do sujeito moderno. Lacan é moderno, paródico: ele se inclui na cena metalingüística como um “cavalo de Tróia”, explorando e representando suas insuficiências, cavando a falta. No jogo do embate entre linguagem e metalinguagem, Lacan se posiciona “do lado” da fala. Trata-se do ato ético que estrutura sua posição de sujeito, isto é, que estrutura de antemão sua realidade - o drama lacaniano, que inclui seu trabalho teórico.

\footnotetext{
${ }^{7}$ Ainda Melman: "Diante do progresso notável da ciência, a existência do inconsciente seguramente é um refúgio para a humanidade. É, por fim, o último lugar que fornece um abrigo para o sujeito, o coloca em posição de operar uma retirada, então, de lançar um olhar para o desenrolar de sua vida, de fazer sobre ela um julgamento e de ser capaz de tomar decisões" (p. 131). "É muito claro que o progresso da ciência nos 'barra' como sujeitos (...). A ciência está cada vez mais presente, exigente, galopante. É a organizadora, a companhia que regula o essencial de nosso mundo. Ela nos coloca numa situação em que cada vez nos é mais difícil nos afirmar, ser considerado como sujeito” (MELMAN, 2003, p. 131-2).

${ }^{8}$ Trata-se do que Lacan chama a afânise do sujeito.
} 


\section{REFERÊNCIAS}

LACAN, J. O tempo lógico e a asserção de uma certeza antecipada. In: Escritos.

Rio de Janeiro: Jorge Zahar, 1998a, [1945].

A coisa freudiana ou sentido do retorno a Freud em psicanálise. In:

Escritos. Rio de Janeiro: Jorge Zahar, 1998b, [1955].

A instância da letra no inconsciente ou a razão desde Freud In: Escritos.

Rio de Janeiro: Jorge Zahar, 1998c, [1957].

A ciência e a verdade. In: Escritos. Rio de Janeiro: Jorge Zahar, 1998d, [1965] [1969-70].

O Seminário. Livro 17, O avesso da psicanálise. Rio de Janeiro: Zahar, 1992,

Seminário 21 - Les non-dupes errent. 1973-1974. (Tradução para o português realizada por uma instituição psicanalítica, não identificada, para “circulação interna”).

MILÁN-RAMOS, J. G. Subjetivação da teoria e angústia na ciência e na psicanálise. In: LEITE, N. (Org.). Corpolinguagem: angústia: o afeto que não engana. Campinas: Mercado de Letras, 2006.

Passar pelo escrito. Campinas, SP: Mercado de Letras, 2007.

MILNER, J. C. O amor da língua. Porto Alegre: Artes Médicas, 1987, [1978].

A obra clara [1995]. Rio de Janeiro: Jorge Zahar, 1996.

ZIZEK, S. El sublime objeto de la ideología. México, DF: Siglo XXI, 1992, [1989].

Porque no saben lo que hacen. El goce como un factor político. Buenos Aires:

Paidós, 1998, [1991]. 

Universidade do Vale do Rio Verde (Unincor). Outras publicações: Hombres de palabra, Montevidéu: Universidad de la Repúblical Lapzus, 2005; Passar pelo Escrito: Uma introdução ao trabalho teórico de Jacques Lacan. Campinas, SP: Mercado de Letras/ Fapesp, 2007. Email: jgmilan@terra.com.br 